\title{
2019 Audited schedule of changes in net assets
}

\section{BKD}

See end of article for authors' affiliations.

The table below summarizes the association's financial status as of December 31, 2019. For a more complete audit report and related information, see the Audited Financial Statements 2001-2019

(members only). This report includes balance sheets, fund status reports, budgeted and actual revenues and expenditures, and a schedule of investments. Members may obtain a copy of the audit report from MLA headquarters.

Table 1 Medical Library Association schedule of changes in net assets by fund year ended December 31, 2019

\begin{tabular}{|c|c|c|c|c|c|c|}
\hline & $\begin{array}{c}\text { Net assets } \\
\text { January 1, } \\
2019 \\
\end{array}$ & $\begin{array}{c}\text { Contributions } \\
\text { and other } \\
\text { revenue }\end{array}$ & $\begin{array}{l}\text { Invest- } \\
\text { ment } \\
\text { return }\end{array}$ & $\begin{array}{l}\text { Net assets } \\
\text { released } \\
\text { from } \\
\text { restrictions } \\
\end{array}$ & Expenses & $\begin{array}{c}\text { Net assets } \\
\text { December } \\
31,2019 \\
\end{array}$ \\
\hline \multicolumn{7}{|l|}{$\begin{array}{l}\text { Net assets without } \\
\text { donor restrictions }\end{array}$} \\
\hline General operating & $(\$ 150,671)$ & $\$ 2,727,216$ & - & - & $(\$ 3,003,435)$ & $(\$ 426,890)$ \\
\hline \multicolumn{7}{|l|}{ Other funds: } \\
\hline $\begin{array}{l}\text { Association } \\
\text { stabilization }\end{array}$ & $\$ 1,688,760$ & - & $\$ 321,738$ & - & $(\$ 39,409)$ & $\$ 1,971,089$ \\
\hline Capital equipment & $\$ 2,228$ & - & - & - & - & $\$ 2,228$ \\
\hline Special purpose & - & - & - & $\$ 124,228$ & $(\$ 124,228)$ & - \\
\hline Sections & $\$ 277,213$ & $\$ 41,150$ & - & - & $(\$ 74,042)$ & $\$ 244,321$ \\
\hline $\begin{array}{l}\text { Total net assets without } \\
\text { donor restrictions }\end{array}$ & $\$ 1,968,201$ & $\$ 41,150$ & $\$ 321,738$ & $\$ 124,228$ & $(\$ 237,679)$ & $\$ 2,217,638$ \\
\hline \multicolumn{7}{|l|}{$\begin{array}{l}\text { Net assets with donor } \\
\text { restrictions }\end{array}$} \\
\hline $\begin{array}{l}\text { Ysabel Bertolucci MLA } \\
\text { Annual Meeting Grant } \\
\text { Endowment }\end{array}$ & $\$ 31,774$ & $\$ 100$ & $\$ 7,425$ & $(\$ 1,323)$ & - & $\$ 37,976$ \\
\hline $\begin{array}{l}\text { Estelle Brodman } \\
\text { Award for the } \\
\text { Academic Medical } \\
\text { Librarian of the Year } \\
\text { Endowment }\end{array}$ & $\$ 73,205$ & - & $\$ 7,274$ & $(\$ 817)$ & - & $\$ 79,662$ \\
\hline $\begin{array}{l}\text { Naomi C. Broering } \\
\text { Hispanic Heritage } \\
\text { Grant Endowment }\end{array}$ & $\$ 27,743$ & $\$ 50$ & $\$ 6,308$ & $(\$ 2,274)$ & - & $\$ 31,827$ \\
\hline $\begin{array}{l}\text { Lois Ann Colaianni } \\
\text { Award for Excellence } \\
\text { and Achievement in } \\
\text { Hospital Librarianship } \\
\text { Endowment }\end{array}$ & $\$ 26,818$ & - & $\$ 4,038$ & $(\$ 676)$ & - & $\$ 30,180$ \\
\hline
\end{tabular}


Table 1 Medical Library Association schedule of changes in net assets by fund year ended December 31, 2019 (continued)

\begin{tabular}{|c|c|c|c|c|c|c|}
\hline & $\begin{array}{c}\text { Net assets } \\
\text { January 1, } \\
2019 \\
\end{array}$ & $\begin{array}{c}\text { Contributions } \\
\text { and other } \\
\text { revenue }\end{array}$ & $\begin{array}{l}\text { Invest- } \\
\text { ment } \\
\text { return }\end{array}$ & $\begin{array}{l}\text { Net assets } \\
\text { released } \\
\text { from } \\
\text { restrictions }\end{array}$ & Expenses & $\begin{array}{c}\text { Net assets } \\
\text { December } \\
31,2019 \\
\end{array}$ \\
\hline $\begin{array}{l}\text { Consumer Health } \\
\text { Librarian of the Year } \\
\text { Award Endowment }\end{array}$ & $\$ 25,898$ & - & $\$ 6,388$ & $(\$ 1,278)$ & - & $\$ 31,008$ \\
\hline $\begin{array}{l}\text { Cunningham } \\
\text { Memorial International } \\
\text { Fellowship } \\
\text { Endowment }\end{array}$ & $\$ 153,322$ & - & $\$ 30,346$ & $(\$ 5,321)$ & - & $\$ 178,347$ \\
\hline $\begin{array}{l}\text { Louise Darling Medal } \\
\text { for Distinguished } \\
\text { Achievement in } \\
\text { Collection } \\
\text { Development in the } \\
\text { Health Sciences } \\
\text { Endowment }\end{array}$ & $\$ 82,350$ & - & $\$ 8,918$ & $(\$ 1,388)$ & - & $\$ 89,880$ \\
\hline $\begin{array}{l}\text { Janet Doe Lectureship } \\
\text { Endowment }\end{array}$ & $\$ 56,914$ & $\$ 300$ & $\$ 6,549$ & $(\$ 785)$ & - & $\$ 62,978$ \\
\hline $\begin{array}{l}\text { Carla J. Funk } \\
\text { Governmental } \\
\text { Relations Award } \\
\text { Endowment }\end{array}$ & $\$ 19,884$ & $\$ 1,442$ & $\$ 4,168$ & $(\$ 180)$ & - & $\$ 25,314$ \\
\hline $\begin{array}{l}\text { Eugene Garfield } \\
\text { Research Fellowship } \\
\text { Endowment }\end{array}$ & $\$ 132,075$ & $\$ 166$ & $\$ 30,847$ & $(\$ 1,342)$ & - & $\$ 161,746$ \\
\hline $\begin{array}{l}\text { T. Mark Hodges } \\
\text { International Service } \\
\text { Award Endowment }\end{array}$ & $\$ 4,656$ & - & $\$ 1,224$ & $(\$ 53)$ & - & $\$ 5,827$ \\
\hline $\begin{array}{l}\text { Hospital Libraries } \\
\text { Section/MLA } \\
\text { Professional } \\
\text { Development Grant } \\
\text { Endowment }\end{array}$ & $\$ 48,230$ & - & $\$ 6,899$ & $(\$ 693)$ & - & $\$ 54,436$ \\
\hline $\begin{array}{l}\text { David A. Kronick } \\
\text { Traveling Fellowship } \\
\text { Endowment }\end{array}$ & $\$ 19,923$ & - & $\$ 8,079$ & $(\$ 352)$ & - & $\$ 27,650$ \\
\hline $\begin{array}{l}\text { Joseph Leiter } \\
\text { NLM/MLA } \\
\text { Lectureship } \\
\text { Endowment }\end{array}$ & $\$ 78,433$ & - & $\$ 10,499$ & $(\$ 10,457)$ & - & $\$ 78,475$ \\
\hline $\begin{array}{l}\text { Librarians without } \\
\text { Borders® Ursula } \\
\text { Poland International } \\
\text { Scholarship } \\
\text { Endowment }\end{array}$ & $\$ 27,232$ & - & $\$ 5,749$ & $(\$ 1,250)$ & - & $\$ 31,731$ \\
\hline
\end{tabular}


Table 1 Medical Library Association schedule of changes in net assets by fund year ended December 31, 2019 (continued)

\begin{tabular}{|c|c|c|c|c|c|c|}
\hline & $\begin{array}{c}\text { Net assets } \\
\text { January 1, } \\
2019\end{array}$ & $\begin{array}{c}\text { Contributions } \\
\text { and other } \\
\text { revenue }\end{array}$ & $\begin{array}{l}\text { Invest- } \\
\text { ment } \\
\text { return }\end{array}$ & $\begin{array}{l}\text { Net assets } \\
\text { released } \\
\text { from } \\
\text { restrictions }\end{array}$ & Expenses & $\begin{array}{c}\text { Net assets } \\
\text { December } \\
31,2019 \\
\end{array}$ \\
\hline $\begin{array}{l}\text { Donald A. B. Lindberg } \\
\text { Research Fellowship } \\
\text { Endowment }\end{array}$ & $\$ 302,139$ & $\$ 5,300$ & $\$ 54,376$ & $(\$ 12,366)$ & - & $\$ 349,449$ \\
\hline $\begin{array}{l}\text { Majors/MLA Chapter } \\
\text { Project of the Year } \\
\text { Endowment }\end{array}$ & $\$ 18,583$ & - & $\$ 2,836$ & $(\$ 623)$ & - & $\$ 20,796$ \\
\hline $\begin{array}{l}\text { Lucretia W. McClure } \\
\text { MLA Excellence in } \\
\text { Education Award } \\
\text { Endowment }\end{array}$ & $\$ 53,656$ & $\$ 980$ & $\$ 9,250$ & (\$903) & - & $\$ 62,983$ \\
\hline $\begin{array}{l}\text { John P. McGovern } \\
\text { Award Lectureship } \\
\text { Endowment }\end{array}$ & $\$ 126,951$ & $\$ 500$ & $\$ 28,624$ & $(\$ 6,246)$ & - & $\$ 149,829$ \\
\hline $\begin{array}{l}\text { MLA Disaster Relief } \\
\text { Fund }\end{array}$ & $\$ 6,354$ & - & - & - & - & $\$ 6,354$ \\
\hline $\begin{array}{l}\text { Scholarship } \\
\text { Endowment }\end{array}$ & $\$ 253,915$ & $\$ 16,870$ & $\$ 85,975$ & $(\$ 12,274)$ & - & $\$ 344,486$ \\
\hline $\begin{array}{l}\text { Section Project of the } \\
\text { Year Award } \\
\text { Endowment }\end{array}$ & $(\$ 642)$ & - & - & $(\$ 500)$ & - & $(\$ 1,142)$ \\
\hline $\begin{array}{l}\text { Shaping Our Future } \\
\text { Endowment }\end{array}$ & $\$ 69,920$ & $\$ 1,600$ & $\$ 12,971$ & $(\$ 564)$ & - & $\$ 83,927$ \\
\hline $\begin{array}{l}\text { Special } \\
\text { Purpose/Librarians } \\
\text { without Borders® }\end{array}$ & $\$ 139,081$ & - & - & $(\$ 40,239)$ & - & $\$ 98,842$ \\
\hline $\begin{array}{l}\text { Special } \\
\text { Purpose/MLA/NLM } \\
\text { Spectrum Scholarships }\end{array}$ & $\$ 26,000$ & - & - & $(\$ 22,324)$ & - & $\$ 3,676$ \\
\hline $\begin{array}{l}\text { Total net assets with } \\
\text { donor restrictions }\end{array}$ & $\$ 1,804,414$ & $\$ 27,308$ & $\$ 338,743$ & $(\$ 124,228)$ & - & $\$ 2,046,237$ \\
\hline Total all net assets & $\$ 3,621,944$ & $\$ 2,795,674$ & $\$ 660,481$ & - & $(\$ 3,241,114)$ & $\$ 3,836,985$ \\
\hline
\end{tabular}

\section{AUTHORS' AFFILIATIONS}

BKD, CPAs and Advisors, on behalf of the Medical Library Association, kelly.weaver@mci-group.com, Chicago, IL 